\title{
Grease film evolution in rolling elastohydrodynamic lubrication contacts
}

\author{
Xinming LI $^{1, *}$, Feng GUO ${ }^{1}$, Gerhard POLL ${ }^{2}$, Yang FEI ${ }^{1}$, Ping YANG ${ }^{1}$ \\ ${ }^{1}$ School of Mechanical and Automotive Engineering, Qingdao University of Technology, Qingdao 266250, China \\ ${ }^{2}$ Institute of Machine Design and Tribology, Leibniz University Hannover, Hannover 30167, Germany \\ Received: 18 December 2019 / Revised: 13 February 2020 / Accepted: 07 March 2020 \\ (C) The author(s) 2020 .
}

\begin{abstract}
Although most rolling element bearings are grease lubricated, the underlying mechanisms of grease lubrication has not been fully explored. This study investigates grease film evolution with glass disc revolutions in rolling elastohydrodynamic lubrication (EHL) contacts. The evolution patterns of the grease films were highly related to the speed ranges and grease structures. The transference of thickener lumps, film thickness decay induced by starvation, and residual layer were recognized. The formation of an equilibrium film determined by the balance of lubricant loss and replenishment was analyzed. The primary mechanisms that dominate grease film formation in different lubricated contacts were clarified.
\end{abstract}

Keywords: grease lubrication; rolling contacts; starvation; replenishment; elastohydrodynamic lubrication (EHL)

\section{Introduction}

As a primary method for rolling element bearing lubrication, grease lubrication has been extensively studied both on model test apparatus and on a full bearing testing bench $[1,2]$. However, the underlying mechanisms of grease lubrication are too complicated to be fully explored. Unlike conventional oil lubrication where film thickness can be calculated through a simple formula [3], grease film thickness can be predicted with less confidence. Apart from the dimensionless parameters of speed, load, material, and geometry [3], additional parameters due to the nature of the grease, such as structure, thickener type, concentration, and so on [4-11], and especially the inlet grease amount [12-15], will have an equal or even more significant influence on film thickness determination. Greases are usually classified as non-Newtonian substances with yield shear stress (Bingham plastic) [16], providing different rheological responses to both shear rate (viscoelasticity) [17] and shear duration (thixotropy) [18]. Below its yield shear stress, the bulk grease is retained, and acts as a reservoir and seal [19], and it does not readily reflow to induce starvation [12-15] and form a corrugated cavitation pattern at both sides of the rolling track $[12,13,20,21]$. Under fully flooded conditions, the variations of effective/apparent viscosity with shear rate (shear thinning effect) cause the film thickness to decrease initially and then increase with speed, forming a " $\mathrm{V}$ "-shaped curve [8, 21-24]. Under constant speed with single charge, the film thickness initially exceeds that of the corresponding base oil and then rapidly decreases to below that of the base oil level, mainly due to the progressive starvation in combination with continuous shear degradation [12-15, 20]. Such an evolution pattern over time or disc revolutions was recognized by different testing methods, such as electrical capacitance [25], magnetic reluctance [26], and optical interferometry [12-15, 20, 27]. The changes in the rheological properties of the inlet grease largely govern the behavior of the elastohydrodynamic lubrication (EHL) films.

Another additional inlet parameter, the inlet lubricant amount, is crucial for film formation [20, 28]. A partially

* Corresponding author: Xinming LI, E-mail: mexinmingli@163.com 
filled inlet gap will suppress the ability of surface separation due to limited hydrodynamic pressure buildup and subsequently reduce the film thickness, resulting in starvation [28]. A grease with consistency related to yield shear stress is more prone to induce starvation because the reflow of bulk grease is restricted [20]. Thus, starvation is frequently encountered in grease-lubricated rolling bearings [1, 19]. The degree of starvation is essentially determined by the rate of lubricant loss from the track and the rate of lubricant replenishment from the track sides [29]. Basically, lubricant replenishment can occur under forces of surface tension and capillary [29-31]. However, the replenishment rate is affected by the lubricant mobility, which is closely related to the shear degree of the worked grease and temperature [14, 32]. Depending on the balance between the rates of lubricant loss and replenishment, four characteristic evolutions of film thickness over time can be recognized, namely, fully flooded, monotonically starved, starved with stabilization, and starved with recovery [33]. Although high film thickness is maintained under fully flooded conditions, it is not favorable because of the excessive heat generation as well as the resulting short grease life. One advantage of grease over base oil alone is that an immobile residual layer is generated on the track, which has a significant effect on surface separation $[6,12,14,15,20,34,35]$. In the absence of a bulk grease supplement, at low temperatures for example, the residual layer will constantly deteriorate by repeated transference of the rolling element, resulting in monotonically starved contacts. The situation of stabilization film or equilibrium film indicates a feed-loss balance where film formation is attributed to both the residual layer and a component of the hydrodynamic film [14, 20, 32] induced by local lubricant replenishment $[13,35,36]$. The mechanism of feed-loss balance also exists in rolling bearings, where permanent lubricant loss due to evaporation, oxidation, and polymerization, among others, should be considered [37]. Film thickness recovery behind the starvation stage may occur if the grease in the vicinity of the track is overly sheared and more bleeding oil is released [38]. In view of the reflow mechanism under surface tension [20], physical or chemical surface treatment has a significant effect on lubricant replenishment, which will also result in a pronounced film recovery [39-41]. High temperature softens the bulk grease and enhances the oil bleeding rate, which may result in bulk grease reflow and subsequently contribute to both the residual layer reformation and hydrodynamic film generation [14, 32]. A similar situation is encountered in rolling bearings where chaotic behavior exists [42].

Unlike the situations using model test devices where fully flooded contacts can be achieved by channeling grease back into the track via a scoop [8, 22-24], grease replenishment in rolling bearings is intermittent or occasional [36]. After the churning phase, grease permeates and remains at different locations in the rolling bearings [42]. Various effects, such as rolling element spin [13], stop-restart [36], temperature [42], cage clearance [43], vibration or transient loading [44], and centrifugal force [45], among others, improve grease replenishment directly by dropping grease lumps from bulk [42], grease redistribution [43], or changing the grease flow around the contacts [20]. A temporary addition of grease lumps will reverse the film decay process [42], during which a feed-loss balance may be well maintained under some of the effects outlined above. The repeated dynamic courses of film decay-reconstruction ensure the safe service of the rolling bearings for a long period of time.

The use of optical EHL apparatus is beneficial to reproduce the evolution process of grease films [46, 47]. Under a single charge of fresh grease, the variation in contact conditions with time, from fully flooded to different starvation levels, can be recorded. The effects of the residual layer and local replenishment are more noticeable under the starved regime than that of a fully flooded state. Moreover, some time-dependent parameters such as the rheological properties of grease, inlet supply conditions, and shear degradation degree can be recognized or deduced from observations. Therefore, this study aims to simulate an evolution process of film thickness over disc revolutions. Different evolution patterns of film thickness depending on rolling speed and grease structures will be presented. In this manner, the underlying mechanisms of grease lubrication and the functions of EHL film components are re-examined and clarified, which may be beneficial to understand the entire lubricating process caused 
by an occasional drop of bulk grease into the rolling bearings.

\section{Experimental}

\subsection{Experimental apparatus and scheme}

An optical test rig was employed to measure EHL films. A schematic of the test rig and the measurement scheme are shown in Fig. 1. A circular contact was formed between a steel ball with $25.4 \mathrm{~mm}$ diameter and a transparent glass disc. The glass disc was mounted on a spindle, which was driven via a flexible coupling by a servo-motor. The ball was located on two dual-cone rollers, leaving one degree of freedom to achieve almost pure roll running when driven by the glass disc. A chromium layer was coated on the loading side of the glass disc to obtain contrasted images. Two laser beams with wavelengths of $532 \mathrm{~nm}$ (green) and $630 \mathrm{~nm}$ (red) were taken as incident light. A dichromatic interference intensity modulation approach was used for film thickness acquisition and film profile reconstruction; the details have been described elsewhere [48, 49].

\subsection{Experimental conditions and lubricant properties}

The experimental conditions are listed in Table 1 . Both grease and base oil were tested for comparison. Before each test, a fixed amount of $2.0 \mathrm{~g}$ of fresh grease

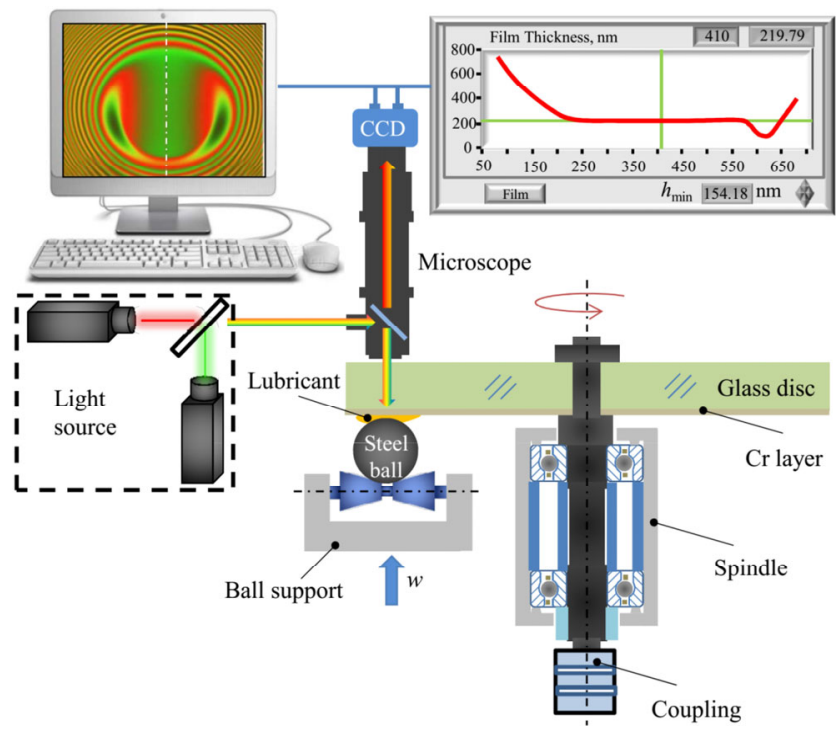

Fig. 1 Schematic diagram of the test rig and measurement scheme.
Table 1 Test conditions.

\begin{tabular}{cc}
\hline Entrainment speed $\left(\mathrm{mm} \cdot \mathrm{s}^{-1}\right)$ & $16,32,63,96,192,288,384,512$ \\
Load $(\mathrm{N}), P_{\mathrm{Hz}}(\mathrm{GPa})$ & $30,0.49$ \\
Base oil amount & Fully flooded \\
Grease amount $(\mathrm{g})$ & 2.0 \\
Temperature $\left({ }^{\circ} \mathrm{C}\right)$ & $20.0 \pm 1.0$ \\
\hline
\end{tabular}

was deliberately applied to the glass surface and no further grease was added during the test. A series of measurements of the film thickness were taken to observe its evolution with the number of disc revolutions at a constant speed. At each speed, the interferograms were captured under a fixed number of disc cycles.

Two types of model grease with the same lithiumhydroxystearate thickener and mineral base oil $500 \mathrm{~N}$ were used in the experiments. The properties of the greases and base oil are listed in Table 2.

The two greases contained an identical soap concentration of $7.8 \mathrm{wt} \%$, but they were manufactured by different processes to produce two types of thickener structures. It is known that the growth of thickener fibers is determined by the cooling rate and time, which can be controlled by adjusting the amount of cooling oil [50]. Thus, the test grease with fine (Grease A) and coarse (Grease B) fibers were produced by cooling with $50 \mathrm{~g}$ of cold oil and by natural cooling, respectively. The morphologies of the two grease thickener fibers were characterized with a scanning electron microscope (SEM), as shown in Fig. 2. The fibers of Grease B produced with a low cooling rate are relatively thick compared with those of Grease A.

Figure 3 compares the variations in the storage modulus $G^{\prime}$, loss modulus $G^{\prime \prime}$, and shear stress $\tau$ with shear strains. The rheological results were obtained from an Anton Paar MCR302 rheometer using plateto-plate geometry. The blue dots indicate the boundaries of the linear viscoelastic (LVE) region, below which $G^{\prime}$ and $G^{\prime \prime}$ are stable due to the near equilibrium state of the grease microstructure. The red dots denote the structure transition points from solid-like to liquid-like beyond the LVE region. The stress corresponding to the transition reflects the entanglement level and structure strength of the grease. The stress at the transition point of Grease B is close to that of Grease A, which is in accordance with the similar value for 
Table 2 Properties of the lubricants used in the experiments.

\begin{tabular}{|c|c|c|c|c|c|c|c|c|}
\hline \multirow{2}{*}{ Grease } & \multicolumn{2}{|c|}{$\begin{array}{l}\text { Viscosity of base oil } \\
500 \mathrm{~N}\left(\mathrm{~mm}^{2} \cdot \mathrm{s}^{-1}\right)\end{array}$} & \multirow{2}{*}{$\begin{array}{c}\text { Thickener } \\
\text { concentratio } \\
\mathrm{n}(\mathrm{wt} \%)\end{array}$} & \multirow{2}{*}{$\begin{array}{l}\text { Cold oil } \\
\text { amount }(\mathrm{g})\end{array}$} & \multicolumn{2}{|c|}{$\begin{array}{l}\text { Dynamic bleeding } \\
\text { ratio }(V / V)\end{array}$} & \multirow{2}{*}{$\begin{array}{c}\text { Cone } \\
\text { penetration } \\
(0.1 \mathrm{~mm})\end{array}$} & \multirow{2}{*}{$\begin{array}{l}\text { National Lubricating } \\
\text { Grease Institute } \\
\text { (NLGI) grade }\end{array}$} \\
\hline & $40^{\circ} \mathrm{C}$ & $100^{\circ} \mathrm{C}$ & & & $6 \mathrm{~h}$ & $24 \mathrm{~h}$ & & \\
\hline Grease A & 90 & 10 & 7.8 & 50 & 28.9 & 46.5 & 281 & 2 \\
\hline Grease B & 90 & 10 & 7.8 & 0 & 53.6 & 62.5 & 286 & 2 \\
\hline
\end{tabular}
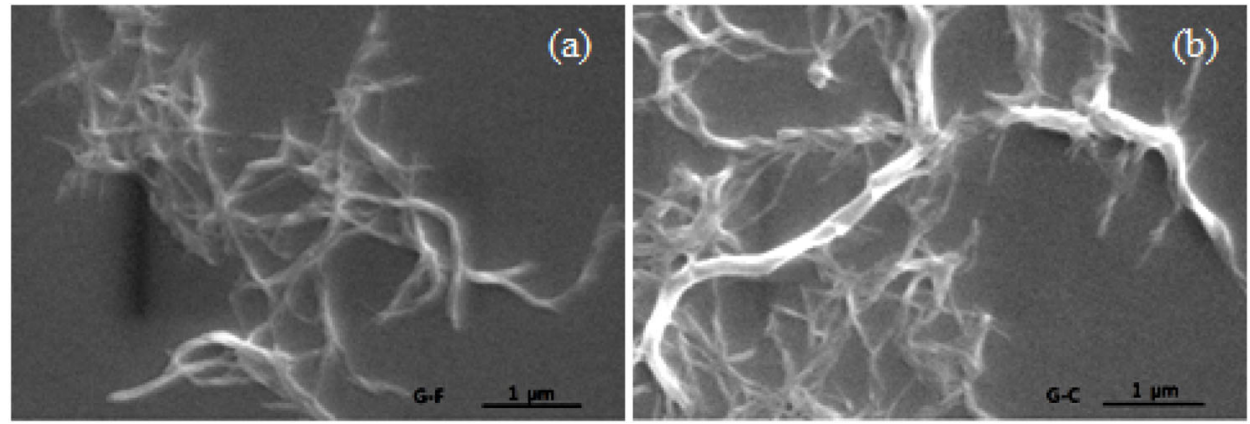

Fig. 2 SEM images of grease thickener fibers under different cooling rates: (a) Grease A and (b) Grease B.

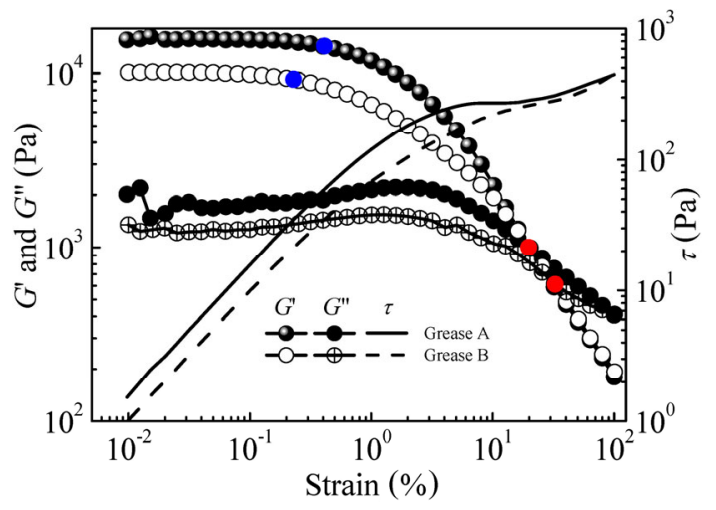

Fig. 3 Storage modulus $G^{\prime}$, loss modulus $G^{\prime \prime}$, and shear stress $\tau$ of two greases.

cone penetration listed in Table 2. Lubricant samples were prepared by Qingdao Lubemater Co., Ltd.

\section{Results}

\subsection{Effect of entrainment velocity on grease film evolution}

Film thickness measurements were performed with both greases and the corresponding base oil. The evolution of the central film thickness $h_{\text {cen }}$ with the number of disc revolutions $N$ at a constant entrainment velocity was recorded. The evolution patterns at low, moderate, and elevated velocities were compared to recognize the effect of entrainment velocity on grease film formation.
A plot of the film thickness as a function of disc revolutions at low velocities is presented in Fig. 4(a). Over the entire range of disc revolutions, the grease film thickness exceeds that of the base oil. An overall increase in film thickness with an increase in speed was found. The corresponding interference images are also given in Fig. 4(b), where $u_{\mathrm{e}}$ denotes the rolling direction. All images show a typical horseshoe film shape with the appearance of "strips" in the direction of $u_{\mathrm{e}}$ in the contact zone, e.g., at $u_{\mathrm{e}}=16$ and $32 \mathrm{~mm} / \mathrm{s}$. The strips actually demonstrate the transference of the thickener lumps, which enhances the grease films and causes slight fluctuations in film curves due to the thickener transferences. From the images, it is also evident that the thickness of the grease films is higher than that of the base oil alone, and the difference is more pronounced at the higher speed of $u_{\mathrm{e}}=63 \mathrm{~mm} / \mathrm{s}$.

As the speed increases, Fig. 5(a) shows that a highlevel film thickness cannot always be maintained but decays against the number of disc revolutions. At $u_{\mathrm{e}}=$ $96 \mathrm{~mm} / \mathrm{s}$, an initial flat stage is temporarily maintained, followed by a rapid decrease in the film thickness. A direct decay is found when the speed reaches $192 \mathrm{~mm} / \mathrm{s}$. Both curves tend to level off which indicates that the decay is time independent. The eventual stabilized film is an equilibrium film produced by the mechanism of feed-loss balance. This representative evolution pattern that indicates a film thickness that is initially high followed by a progressive decrease 

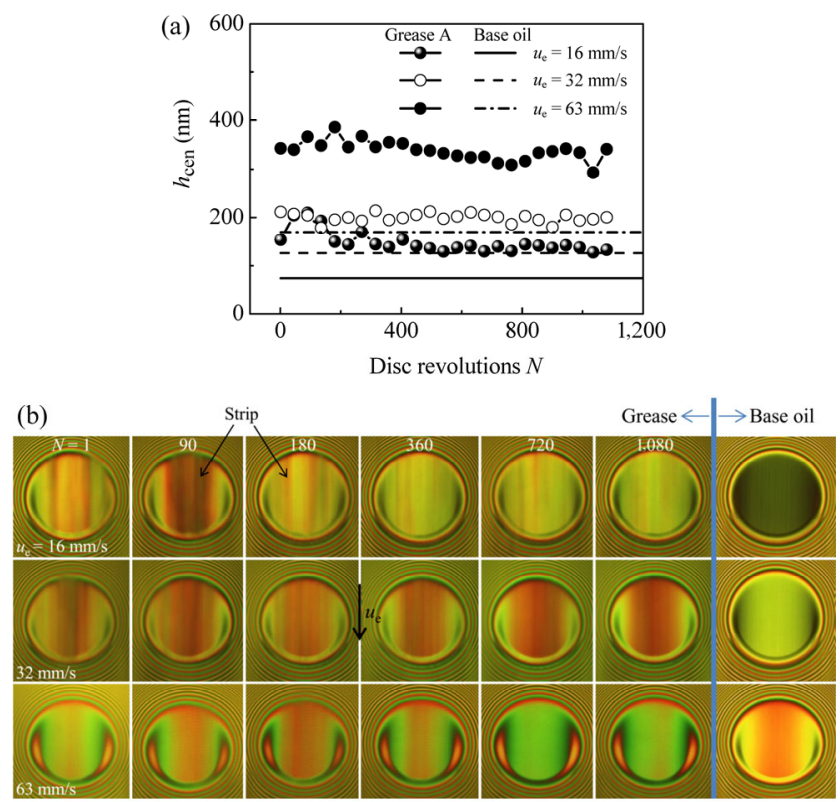

Fig. 4 Evolution of EHL films against disc revolutions at low speeds, Grease A. (a) Variations of film thickness with disc revolutions; (b) interference images.
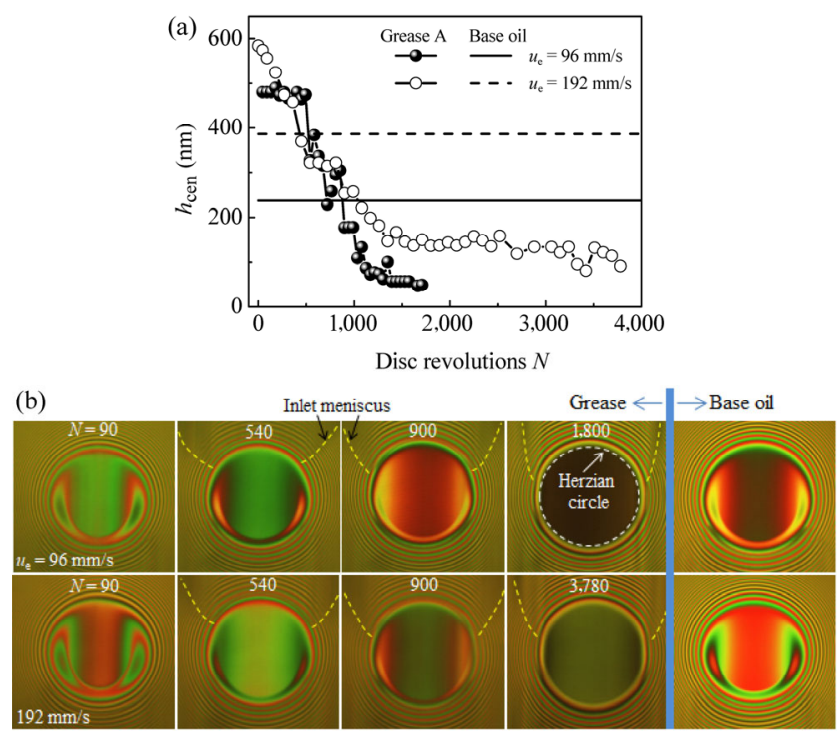

Fig. 5 Evolution of EHL films against disc revolutions at moderate speeds, Grease A. (a) Variations of film thickness with disc revolutions; (b) interference images.

before it finally becomes less than that of the base oil alone, has been extensively observed in previous studies [12-15, 20, 25-27]. The film decay is primarily induced by starvation which is characterized by an inlet oil-air meniscus as presented in Fig. 5(b). The inlet meniscus, denoted by yellow dashed lines, is seen to be inside the Hertzian circle (white dash circle). Although the inlet boundaries are at similar locations, the film thickness levels vary significantly depending on the number of disc revolutions; the film thickness is greater than that of the base oil at $N=540$ and close to that of the base oil at $N=900$. At the end of running, a state of fully starved or parched EHL contacts is reached. The continuous film reduction under similar inlet supply conditions indicates a progressive grease thickener breakdown due to consecutive transferences of the steel balls.

However, as the speed is further increased, it is interesting to observe complete film recovery as plotted in Fig. 6(a). At $u_{\mathrm{e}}=416 \mathrm{~mm} / \mathrm{s}$, the contacts experience a short period of lubricant starvation, where the film thickness approaches that of the base oil and then rebounds to a fully flooded state. Starvation is not continuous at $u_{\mathrm{e}}=512 \mathrm{~mm} / \mathrm{s}$ although it occurs occasionally throughout the whole process. Both curves present an initial drop and eventually maintain a much higher level than that of the corresponding base oil. Such situations differ from previous observations under fully flooded conditions [8, 22-24], where the film thicknesses are close to those of the base oil alone under a high-speed regime. The interference images in Fig. 6(b) show the typical fully flooded EHL state with the exception of $N=1,890$ at $u_{\mathrm{e}}=416 \mathrm{~mm} / \mathrm{s}$, where an inlet meniscus emerges in front of the contact, indicating a partial starvation state. All the images
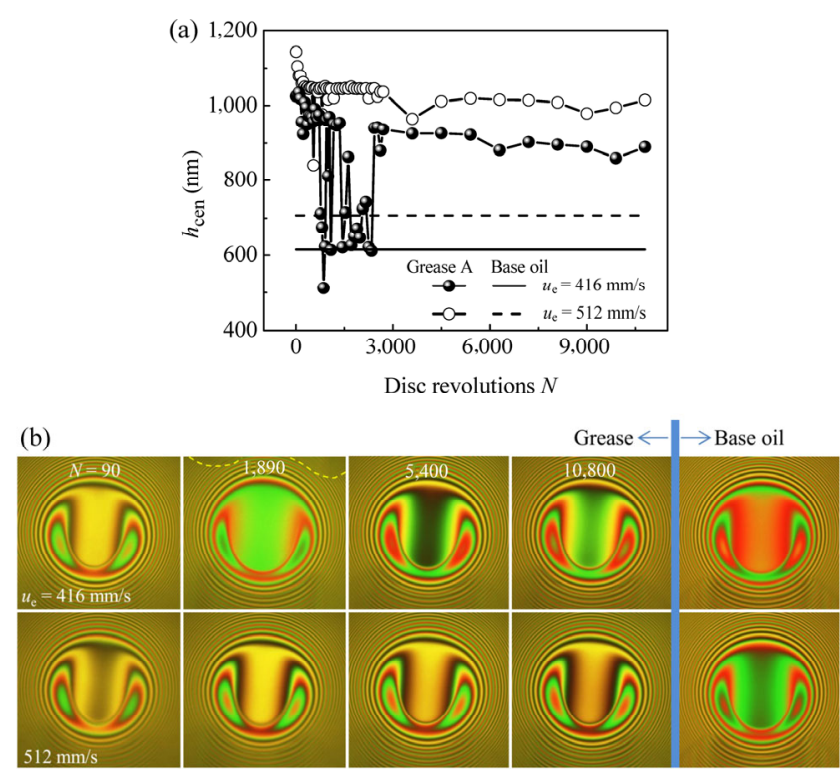

Fig. 6 Evolutions of EHL films against disc revolutions under elevated speeds, Grease A. (a) Variations of film thickness with disc revolutions; (b) interference images. 
with speeds under $u_{\mathrm{e}}=512 \mathrm{~mm} / \mathrm{s}$ are similar, indicating a relatively stable lubrication state.

\subsection{Effect of grease structure on grease film evolutions}

To assess the influence of the thickener structure on film evolution, parallel experiments were conducted using coarse-fibered Grease B under identical running conditions as Grease A.

Figure 7(a) shows a plot of the evolution of grease films at different speeds. High intensity film fluctuation with respect to disc revolutions is clearly displayed at $u_{\mathrm{e}}=16$ and $32 \mathrm{~mm} / \mathrm{s}$. Unlike the situation of Grease A in Fig. 4(b), where typical EHL films are well retained, the contacts for Grease B are totally distorted as shown in Fig. 7(b). A series of large lumps enter the contacts, resulting in the loss of the horseshoe film shape and instant film lift. This lubrication state is a source of noise generation in rolling bearings [8, 19]. By increasing the speed, the thickness fluctuations are reduced; hence, the contact zone resembles that of a normal EHL film, see the process under $u_{\mathrm{e}}=63$ and $96 \mathrm{~mm} / \mathrm{s}$. This is mainly due to successive shear degradation.
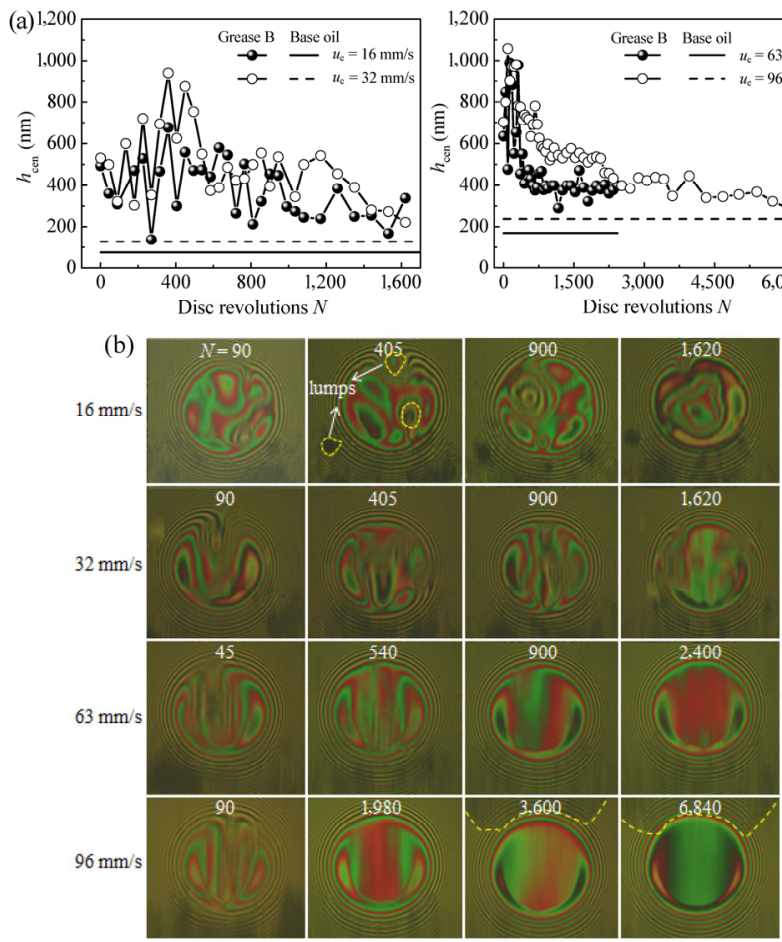

Fig. 7 Evolutions of EHL films against disc revolutions at different speeds, Grease B. (a) Variations of film thickness with disc revolutions; (b) interference images.
Both curves of $u_{\mathrm{e}}=63$ and $96 \mathrm{~mm} / \mathrm{s}$ present a trend of film decay similar to those shown in Fig. 5(a), but the grease curves are consistently above those of the base oil over the entire process. For $u_{\mathrm{e}}=96 \mathrm{~mm} / \mathrm{s}$, another mechanism contributing to the film decay is starvation, which can be recognized from the appearance of the inlet meniscus in the images of $N=3,600$ and 6,840.

Comprehensive comparisons of film evolutions between Grease A and Grease B under the entire test conditions are presented in Fig. 8. For Grease A, at low speeds from 16 to $63 \mathrm{~mm} / \mathrm{s}$, the curves are almost flat with slight fluctuations. At moderate speeds, in the range of $96-228 \mathrm{~mm} / \mathrm{s}$, different film decay patterns are formed. At speeds above $252 \mathrm{~mm} / \mathrm{s}$, the equilibrium film thicknesses become higher and fully flooded states are finally achieved at $u_{\mathrm{e}}=416$ and $512 \mathrm{~mm} / \mathrm{s}$. However, for Grease B, although the initial film thickness is higher than that of Grease B at each speed, all the curves tend to decline as the number of disc revolutions increases. An opposite film evolution trend between Grease A and Grease B is observed as the speed increases from 252 to $512 \mathrm{~mm} / \mathrm{s}$. It is apparent that the film decay is more pronounced with increasing speed. Figure 9 presents the interference images at $u_{\mathrm{e}}=252$ and $512 \mathrm{~mm} / \mathrm{s}$. At each speed, the images are selected in terms of lubrication states, i.e., similar contacts but different number of disc revolutions.
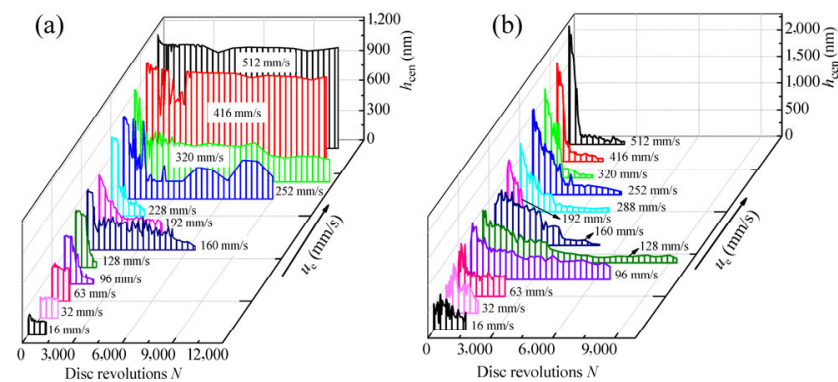

Fig. 8 Comparisons of film evolutions between (a) Grease A and (b) Grease B.

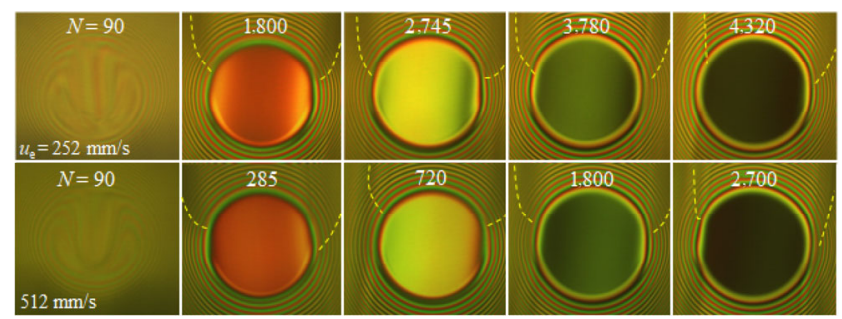

Fig. 9 Evolutions of grease films with disc revolutions, Grease B. 
At $N=90$, the film is too thick and unstable to enable a clear image to be captured. Under full starvation conditions, the thicknesses for $u_{\mathrm{e}}=512 \mathrm{~mm} / \mathrm{s}$ are much lower than those for $u_{\mathrm{e}}=252 \mathrm{~mm} / \mathrm{s}$, indicating a more dramatic film decay.

\section{Mechanisms and discussion}

From the above results, it is evident that the formation of grease films is complicated and is highly dependent on the running time, speed, and thickener structure. The mechanisms that determine the film variations are discussed in this section.

\subsection{Formation of thick film}

Thick grease films are observed in cases of low speeds for both greases, elevated speeds for Grease A, and initial running for all test conditions.

Apparently, the generation of thick grease films is due to the transference of thickener lumps as shown in Fig. 4(b), Fig. 7(b), and previous observations $[8,22-24,51]$. The breakdown of lumps from their intact state to small particles contributes to the transition from distorted contact to normal contact, as shown in Fig. 7(b). Figure 10 shows the initial contact and worked contact at different speeds. It is evident that from the initial contact to the worked contact at $u_{\mathrm{e}}=$ $96 \mathrm{~mm} / \mathrm{s}$, the lumps are gradually sheared into small particles. At $u_{\mathrm{e}}=16 \mathrm{~mm} / \mathrm{s}$, large lumps still remained after work, which corresponds to consistent distorted contacts over the entire running. The smaller particles at $u_{\mathrm{e}}=63$ and $96 \mathrm{~mm} / \mathrm{s}$, indicate a shear degradation process, hence the transition from "noisy" contact to smooth contact.

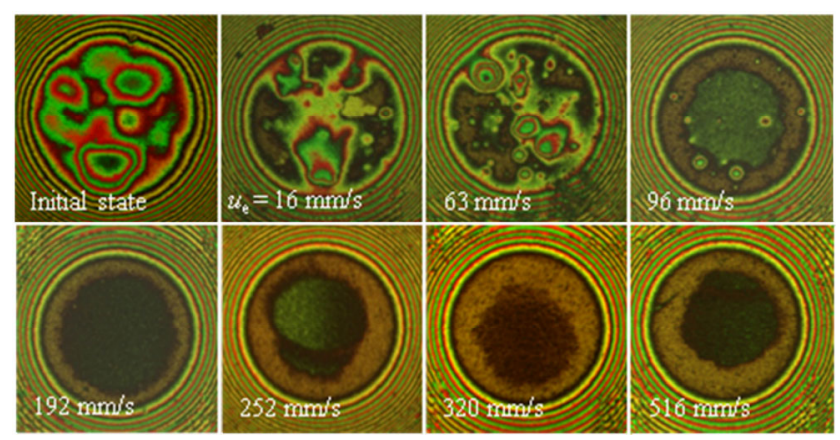

Fig. 10 Initial contacts and worked contacts under static state, Grease B.
Essentially, the apparent viscosity of the inlet lubricant is crucial to determine the film thickness in the contacts. It is believed that the apparent viscosity of the grease at low shear rates (low speeds) will exceed that of the corresponding base oil, resulting in a thicker grease film. As Fig. 10 shows, the partially destroyed lumps at low speeds have an effect on the enhancement of the apparent viscosity. Recently, Kochi et al. observed the aggregation of lumps in the inlet zone and reverse flow of streamers in a radial direction away from the contact [24], which indicates that the concentration of thickener will increase in the inlet zone and thus enhance the film thickness. This observation may support the formation of thick films at low speeds. In the present study, this mechanism may also elucidate the thick film during the initial running period at each speed.

The thick grease films at elevated speeds for Grease A are mainly due to the shear degradation of thickeners. The grease will be subjected to severe shear in the inlet zone under a high shear rate (high speed). The original fibrous structure of the thickener will degrade causing an initial film thickness decay in Fig. 6(a). As the test proceeds, the grease is heavily sheared in the inlet zone and eventually breaks down into discrete particles or fine fibers that disperse in the base oil. In this situation, the viscosity of the fully sheared grease is $\eta_{\mathrm{G}}=\eta_{\mathrm{BO}}(1+B \Phi)$, where $\eta_{\mathrm{BO}}$ is the viscosity of the base oil, $B$ is a constant, and $\Phi$ is the volume fraction of the thickener [8]. Consequently, the grease, as a high viscous material, has a large film thickness, as shown in Fig. 6(a). The difference between this and previous investigations into the variations of film thickness against speed [8, 22-24] is that the grease film thickness in the current study is much greater than that of the base oil alone, whereas the film thicknesses with grease and base oil are similar $[8,22-24]$. A possible explanation for this is the different rheological properties of the grease, which depend on the test procedure. In the film thickness-speed tests, a "V"-shaped film curve is generally formed. The initial decrease in film thickness with speed should be attributed to the shear thinning effect (viscoelasticity), since the "V" shape can be well maintained under repeated speed increase and decrease $[8,24]$ or if it is pre-sheared [22]. Otherwise, a loss of the "V" shape 
may be observed if permanent physical destruction of the bulk grease is considered. The linear increase in film thickness with speed represents a Newtonian flow behavior, indicating that a secondary Newtonian state is reached at high speeds. However, in the present study, the tests are performed at constant speeds, which can be taken as an approximately constant shear rate running condition. This means that in the absence of the shearing effect, the apparent viscosity of the fully sheared grease can be maintained and is higher than the secondary Newtonian value. Under constant shear, the thixotropy may affect the apparent viscosity but this is difficult to ascertain from the results.

\subsection{Mechanisms of film thickness decay}

Different patterns of film thickness decay are shown in Fig. 8. The mechanisms of both shear degradation and starvation can induce film decay [52]. Shear degradation will cause both temporary and permanent apparent viscosity loss, hence reducing the film thickness, as shown for the initial film decay in Figs. 6(a) and 7(a).

Starvation results in rapid and continuous film decay. During the running process, most of the grease is displaced from the track by the squeeze motion and pressure gradient induced cross flow [53] or side flow [54]. The lubricant loss rate is higher than the lubricant replenishment rate mainly due to the high yield stress. The high viscosity induced starvation is gross starvation or bulk starvation, under which the film thickness may still be greater than that of the base oil, see Figs. $5(\mathrm{a})$ and $7\left(u_{\mathrm{e}}=96 \mathrm{~mm} / \mathrm{s}\right)$. Figure $5(\mathrm{~b})$ shows that once bulk starvation occurs, the grease is less likely to be further sheared in the inlet zone; thus, the displaced grease remains "stiff", causing a very low replenishment rate. Therefore, the inlet gap will be continuously depleted, resulting in progressive starvation. However, at elevated speeds $\left(u_{\mathrm{e}}=416 \mathrm{~mm} / \mathrm{s}\right.$, Grease A), in the unstable semi-starvation state, the grease can still be heavily sheared. Hence, the displaced grease is softened, and it develops the ability to reflow easily, allowing the film to return to a fully flooded state.

Unlike the situations with Grease A, the film thickness decay of Grease B is more pronounced at elevated speeds. Figure 4 shows that the structural strength of the two types of grease is similar, but Grease B with its coarse fibers has greater inter-fiber spacing which impart higher bleeding rates, as shown in Table 2. However, although Grease B can release a higher amount of base oil, the released oil is more prone to be expelled from the contact [55]. It is this loss that dominates the film decay. The higher the speed, the shorter the replenishment time and the steeper the film decay.

\subsection{Formation of equilibrium films}

In Figs. 5 and 7 (Grease B, $u_{\mathrm{e}} \geq 218 \mathrm{~mm} / \mathrm{s}$ ), the film thickness eventually reaches an equilibrium state and is less time dependent, which is a feed-loss balance situation.

The grease films are composed of a residual layer and a hydrodynamic film [12, 14, 32]. Besides determining the onset of starvation and oil bleeding, another role of the thickener is that of direct participation in film formation as a stagnant layer. During the first few disc revolutions, a residual layer is formed by the transference of grease lumps and deposition of the degraded grease. Initially, this layer is thick (Fig. 5(b), $N=540$ ), but with consecutive rolling, the layer is milled, and it breaks down, resulting in the loss of more base oil and leaving a highly viscous layer. In this process, the film thickness continuously decreases and finally stabilizes. The residual layer can be recognized from the static tracks in Figs. 10 and 11. Depending on the running conditions and the final equilibrium state, the thickness of the layer varies. In Fig. 11, a higher-level equilibrium film produces a clear residual layer $\left(u_{\mathrm{e}}=228 \mathrm{~mm} / \mathrm{s}\right)$, whereas a more severe starvation leaves an undetectable layer $\left(u_{\mathrm{e}}=160 \mathrm{~mm} / \mathrm{s}\right)$.

Under a heavily starved state, the effect of the residual layer becomes more significant for the separation of the contact surfaces. Figure 12 shows the equilibrium film, static contact after working, and out-of-contact track. Two types of oil reservoirs are formed [13]. The primary reservoirs contribute to a local lubricant replenishment under the capillary force, which is imperative for the hydrodynamic film formation. The secondary reservoirs are mainly responsible for base oil supply. In addition, during the 


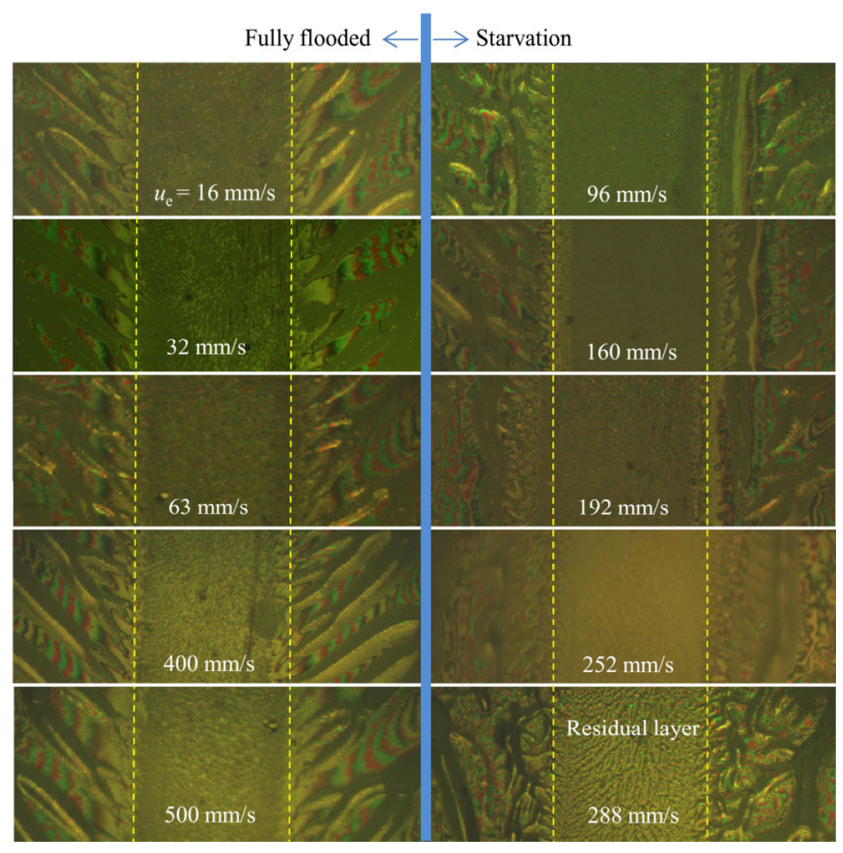

Fig. 11 Static rolling track after running, Grease A.

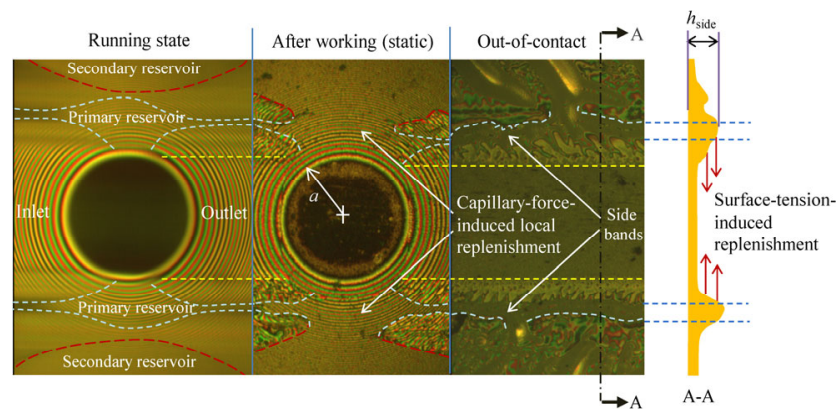

Fig. 12 Equilibrium film and replenishment mechanisms, Grease A, $u_{\mathrm{e}}=128 \mathrm{~mm} / \mathrm{s}$.

out-of-contact period, some lubricant from the side bands may replenish the track, driven by surface tension. The lubricant loss rate determined by the pressure gradient appears to be larger than the rate of spontaneous reflow induced by surface tension forces. In the semi-starved lubrication state, free oil still remains, which can be expelled. However, with heavily starved contacts, very little free oil is squeezed out, and the reflow amount may balance the lubricant loss, subsequently forming an equilibrium film. The thickness of the equilibrium film is determined by both the strength of the residual layer, in terms of separation ability and duration, and the lubricant replenishment ability.

In addition, the lubricant replenishment is also related to the grease flow and distribution at both contact sides, as shown in Fig. 11. Different grease distributions are observed for fully flooded and starved running states. For fully flooded running, the "fingers" formed by cavitation are maintained, and they extend from the bulk grease towards the track, providing a mechanism of lubricant feeding. Close to the track, fine branches are formed due to high shear. However, under the starved running condition, the grease fingers retract from the track and are distributed parallel to the rolling direction to some extent or are finely divided, indicating an adverse effect on lubricant replenishment [20].

Figure 13 schematically shows the different lubrication states experienced by the two types of grease. For the thin-fibered Grease A, fully flooded contacts are formed with a thicker film than that of the corresponding base oil. At moderate speeds, starved contacts occur due to a high lubricant loss rate, which causes progressive film decay and formation of an equilibrium film. At elevated speeds, the fully sheared grease is degraded into fine fibers that disperse into the base oil and form a highly viscous lubricant, which contributes to a thick film and a fully flooded state is achieved again. However, the coarse-fibered Grease B causes intense fluctuations in film thickness at low speeds. The high bleeding rate induces increased lubricant loss and thereby tends to create starvation. High shear rates (high speeds) aggravate the film decay. Thus, Grease B only undergoes stages (I) and (II).

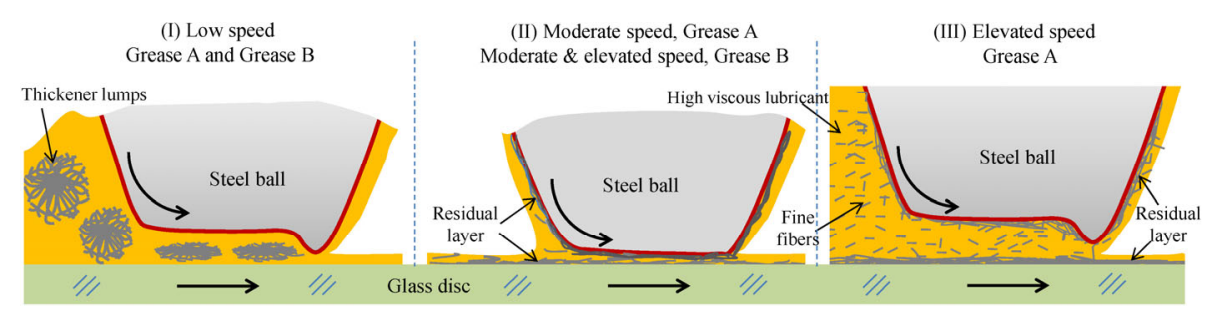

Fig. 13 Schematic of lubrication states over different speed ranges. 


\section{Conclusions}

The evolution of grease film thickness with the number of disc revolutions at different speeds was observed. The influence of the grease structure on the film evolution was analyzed. The current results provide evidence of the transference of thickener lumps, shear degradation, and formation of residual layers. The following conclusions were drawn:

1) At low speeds, both types of grease with thin and coarse fibers form a thicker film than the corresponding base oil, due to the transference of thickener lumps. The grease with coarse fibers produces large lumps which cause intense fluctuations in film thickness.

2) At moderate speeds, progressive film decay occurs due to starvation.

3) At elevated speeds, the grease with thin fibers is fully sheared and degraded, forming a highly viscous lubricant, which can generate a thick film. In contrast, the grease with coarse fibers has a high bleeding rate, resulting in increased lubricant loss and a more pronounced film decay.

4) Both the residual layers and hydrodynamic films contribute to the formation of lubricating films with grease lubrication. The grease flow and distribution at the track sides affect the lubricant replenishment and the formation of equilibrium films.

\section{Acknowledgements}

The authors would like to express their thanks to the financial supports from the National Natural Science Foundation of China (Nos. 51875299 and 51775286) and the Natural Science Foundation of Shandong Province (No. ZR2019MEE044)

Open Access: This article is licensed under a Creative Commons Attribution 4.0 International License, which permits use, sharing, adaptation, distribution and reproduction in any medium or format, as long as you give appropriate credit to the original author(s) and the source, provide a link to the Creative Commons licence, and indicate if changes were made.

The images or other third party material in this article are included in the article's Creative Commons licence, unless indicated otherwise in a credit line to the material. If material is not included in the article's Creative Commons licence and your intended use is not permitted by statutory regulation or exceeds the permitted use, you will need to obtain permission directly from the copyright holder.

To view a copy of this licence, visit http://creativecommons.org/licenses/by/4.0/.

\section{References}

[1] Lugt P M. A review on grease lubrication in rolling bearings. Tribol Trans 52(4): 470-480 (2009)

[2] Baly H, Poll G, Cann P M, Lubrecht A A. Correlation between model test devices and full bearing tests under grease lubricated conditions. In IUTAM Symposium on Elastohydrodynamics and Micro-elastohydrodynamics, 2006: 229-240.

[3] Hamrock B J, Dowson D. Isothermal elastohydrodynamic lubrication of point contacts part 3-fully flooded results. ASME J Lubr Technol 99: 264-276 (1977)

[4] Kageyama H, Machidori W, Moriuchi T. Grease lubrication in elastohydrodynamic contacts. NLGI Spokesman 49: 72-80 (1984)

[5] Dalmaz G, Nantua R. An evaluation of grease behavior in rolling bearing contacts. Lubr Eng 43(12): 905-915 (1986)

[6] Cann P M, Williamson B P, Coy R C, Spike H A. The behaviour of greases in elastohydrodynamic contacts. $J$ Phys D: Appl Phys 25: 124-132 (1992)

[7] Williamson B P. An optical study of grease rheology in an elastohydrodynamic point contact under fully flooded and starvation conditions. Proc IMechE Part J: J Eng Tribol 209(1): 63-74 (1994)

[8] Hurley S, Cann P M. Grease composition and film thickness in rolling contacts. NLGI Spokesman 63(4): 12-22 (1999)

[9] Kaneta M, Ogata T, Takubo Y, Naka M. Effects of a thickener structure on grease elastohydrodynamic lubrication films. Proc IMechE Part J: J Engr Tribol 214: 327-336 (2000)

[10] Couronné I, Vergne P, Mazuyer D, Truong-Dinh N, Girodin D. Nature and Properties of the Lubricating Phase in Grease Lubricated Contact, Tribol Trans 46(1): 37-43 (2003)

[11] Cyriac F, Lugt P M, Bosman R, Padberg C J, Venner C H. Effect of thickener particle geometry and concentration on the grease EHL film thickness at medium speeds. Tribol Lett 61: 18 (2016)

[12] Cann P M, Spikes H A. Film thickness measurements of lubricating greases under normally starved conditions. NLGI Spokesman 52(2): 21-27 (1992)

[13] Åström H, Östensen J O, Höglund E. Lubricating grease 
replenishment in an elastohydrodynamic point contact. $A S M E$ J Tribol 115(3): 501-506 (1993)

[14] Cann P M, Spikes H A. Visualization of starved grease and fluid lubricant films. Tribol Ser 30: 161-166 (1995).

[15] Cann P M. Starved Grease Lubrication of Rolling Contacts. Tribol Trans 42(4): 867-873 (1999)

[16] Whittingstall P, Shah R. Yield stress studies on greases. NLGI Spokesman 62(3): 8-22 (1997)

[17] Yeong S K, Luckham P F, Tadros Th F. Steady flow and viscoelastic properties of lubricating grease containing various thickener concentrations. J Colloid Interface Sci 274(1): 285-293 (2004)

[18] Paszkowski M, Olsztynska-Janus S. Grease thixotropy: evaluation of grease microstructure change due to shear and relaxation. Ind Lubr Tribol 66(2): 223-237 (2014)

[19] Lugt P M. Grease Lubrication in Rolling Bearings. John Wiley and Sons, Ltd., 2013.

[20] Cann P M. Thin-film grease lubrication. Proc IMechE Part J: J Eng Tribol 213(5): 405-416 (1999)

[21] Chen J, Tanaka H, Sugimura J. Experimental study of starvation and flow behavior in grease-lubricated EHD contact. Tribology Online 10(1): 48-55 (2015)

[22] Cen H, Lugt P M, Morales-Espejel G. On the film thickness of grease-lubricated contacts at low speeds. Tribol Trans 57(4): 668-678 (2014)

[23] Goncalves D, Graca B, Campos A V, Seabra J, Leckner J, Westbroek R. On the film thickness behaviour of polymer greases at low and high speeds. Tribol Int 90: 435-444 (2015)

[24] Kochi T, Sakai M, Nogi T, Dong D, Kimura Y. Experimental study on the physics of thick EHL film formation with grease at low speeds. Tribol Lett 67: 55 (2019)

[25] Dyson A, Wilson A R. Film thicknesses in elastohydrodynamic lubrication of rollers by greases. Proc IMechE Part J: J Eng Tribol 184(6): 1-11 (1969)

[26] Poon S Y. Experimental Study of Grease in elastohydrodynamic lubrication. ASME J Lub Tech Trans 94(1): 27-34 (1972)

[27] Aihara S, Dowson D. A study of film thickness in grease lubricated elastohydrodynamic contacts. In Proc of the 5th Leeds-Lyon Symposium on Tribology, 1978: 104-115.

[28] Wedeven L D, Evans D, Cameron A. Optical analysis of ball bearing starvation. ASME J Lub Tech 93(3): 349-361 (1971)

[29] Pemberton J, Cameron A. A mechanism of fluid replenishment in elastohydrodynamic contacts. Wear 37(1): 185-190 (1976)

[30] Chiu Y P. An analysis and prediction of lubricant film formation in rolling contact systems. ASLE Tribol Trans 17:
22-35 (1974)

[31] Jacod B, Pubilier F, Cann PME, Lubrecht A A. An analysis of track replenishment mechanisms in the starved regime. Tribol Ser 36: 483-492 (1998)

[32] Cann P M. Starvation and reflow in a grease lubricated elastohydrodynamic contact. Trib Trans 39: 698-704 (1996)

[33] Merieux J, Hurley S, Lubrecht A A, Cann P M. Sheardegradation of grease and base oil availability in starved EHL lubrication. Tribol Ser 38: 581-588 (2000)

[34] Scarlett N A. Use of Grease in Rolling Bearings. Proc IMechE Part 3A 182: 167-171 (1967)

[35] Cann P M. Understanding grease lubrication. Tribol Ser 31: 573-581 (1996)

[36] Cann P M, Lubrecht A A. Analysis of grease lubrication in rolling element bearings. Lubr Sci 11(3): 227-245 (1999)

[37] Wikström V, Jacobson B. Loss of lubricant from oil-lubricated near-starved spherical roller bearings. Proc IMechE Part J: J Eng Tribol 211(1): 51-66 (1997)

[38] Huang L, Guo D, Wen S H. Film thickness decay and replenishment in point contact lubricated with different greases-A study into oil bleeding and the evolution of lubricant reservoir. Tribol Int 93: 620-627 (2016)

[39] Li X M, Guo F, Wong P L, Zhao Y. Regulation of lubricant supply by wettability gradient in rolling EHL contacts. Tribol Int 120: 565-574 (2018)

[40] Liu C L, Guo F, Wong P L, Li X M. Tribological behaviour of surfaces with stepped wettability under limited lubricant supply. Tribol Int 141: 105880 (2020)

[41] Huang L, Guo D, Liu X, Xie G X, George T Y WAN, Wen $S$ Z. Effects of nano thickener deposited film on the behaviour of starvation and replenishment of lubricating greases. Friction 4(4): 313-323 (2016)

[42] Lugt P M, Velickov S, Tripp J. On the chaotic behavior of grease lubrication in rolling bearings. Trib Trans 52: 581-590 (2009)

[43] Damiens B, Cann P M, Lubrecht A A. Influence of cage clearance on bearing lubrication. Trib Trans 47: 2-6 (2004)

[44] Cann P M, Damiens B, Lubrecht A A. The effect of transient loading on contact replenishment with lubricating greases. Tribol Ser 43: 745-750 (2003)

[45] Gershuni L, Larson MG, Lugt PM. Lubricant replenishment in rolling bearing contacts. STLE Tribol Trans 51(5): 643-651 (2008)

[46] Ma L R, Luo J B. Thin film lubrication in the past 20 years. Friction 4(4): 280-302 (2016)

[47] Li G, Zhang C H, Xu H Y, Luo J B, Liu S. The film behaviors of grease in point contact during microoscillation. Tribol Lett 38(3): 259-266 (2010) 
[48] Liu H C, Guo F, Guo L, Wong P L. A dichromatic interference intensity modulation approach to measurement of lubricating film thickness. Tribol Lett 58(1): 15 (2015)

[49] Guo L, Wong P, Guo F. Identifying the optimal interfacial parameter correlated with hydrodynamic lubrication. Friction 4(4): 347-358 (2016)

[50] Xu N, Li W M, Zhang M, Zhao G Q, Wang X B. New insight to the tribology-structure interrelationship of lubricating grease by a rheological method. $R S C A d v$ 5: 54202-54210 (2015)

[51] Wang Z J, Shen X J, Chen X Y, Tao D H, Shi L, Liu S B. Experimental investigation of EHD grease lubrication in finite line contacts. Friction 7(3): 237-245 (2019)

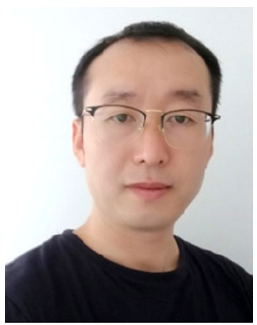

Xinming LI. He got his Ph.D. degree in School of Mechanical Engineering, Qingdao University of Technology in 2012. He is now a full-time associate professor in Qingdao
[52] Han Y M, Wang J, Wang S S, Zou Q, Barber G. Response of grease film at low speeds under pure rolling reciprocating motion. Friction 8(1): 115-135 (2020)

[53] Kingsbury E. Cross flow in a starved EHD contact. ASLE Trans 16(4): 276-280 (1973)

[54] van Zoelen M T, Venner C H, Lugt P M. Prediction of film thickness of film thickness decay in starved elastohydrodynamically lubricated contacts using a thin layer flow model. Proc IMechE Part J: J Eng Tribol 223: 541 (2009)

[55] Cann P M, Chevalier F, Lubrecht A A. Track depletion and replenishment in a grease lubricated point contact-a quantitative analysis. Tribol Ser 32: 405-413 (1997)

University of Technology. His recent research interests include grease and minimal quantity lubrication mechanisms of rolling bearings, lubricant rheology, and lubrication approaches of machine elements. 